\title{
An Acaromyces Species Associated with Bark Beetles from Southern Pine Has Inhibitory Properties Against Raffaelea lauricola, the Causal Pathogen of Laurel Wilt Disease of Redbay
}

\author{
Rabiu Olatinwo ${ }^{1,+}$ and Stephen Fraedrich ${ }^{2}$ \\ ${ }^{1}$ USDA, Forest Service, Southern Research Station, Pineville, LA 71360 \\ ${ }^{2}$ USDA, Forest Service, Southern Research Station, Athens, GA 30602
}

Accepted for publication 15 August 2019.

\section{Abstract}

Laurel wilt is a destructive disease of redbay (Persea borbonia) and other species in the laurel family (Lauraceae). It is caused by Raffaelea lauricola, a fungal symbiont of the redbay ambrosia beetle, Xyleborus glabratus (Coleoptera: Curculionidae), cointroduced into the United States around 2002. During assessments of fungi associated with bark beetles from loblolly pine, an unknown fungus was isolated that appeared to have broad-spectrum antifungal activities. In this study, we identified the unknown fungus and determined the inhibitory effect of its secondary metabolites on $R$. lauricola. DNA analysis identified the fungus as Acaromyces ingoldii (GenBank accession no. EU770231). Secondary metabolites produced by the $A$. ingoldii completely inhibited $R$. lauricola mycelial growth on potato dextrose agar (PDA) plates preinoculated with $A$. ingoldii and reduced $R$ lauricola growth significantly on malt extract agar plates preinoculated with $A$. ingoldii. $R$. lauricola isolates inoculated on PDA plates 7 days after $A$. ingoldii were completely inhibited with no growth or spore germination. Direct evaluation of $A$. ingoldii crude extract on $R$. lauricola spores in a multi-well culture plate assay showed inhibition of spore germination at $10 \%$ and higher concentrations. Secondary metabolites from $A$. ingoldii could be potentially useful in managing the future spread of laurel wilt.

Keywords: biocontrol, integrated pest management, diagnostics, trees, Acaromyces ingoldii, Persea borbonia
Laurel wilt is an important disease that affects members of the Lauraceae including avocado (Persea americana), redbay (Persea borbonia), and sassafras (Sassafras albidum) (Fraedrich et al. 2008). The causal pathogen of the disease is Raffaelea lauricola, a fungal symbiont associated with Xyleborus glabratus (Coleoptera: Curculionidae), the primary insect responsible for disease transmission (Harrington et al. 2008). The first report of the disease in the United States was coincidental with the introduction of $X$. glabratus near Savannah, Georgia, around 2002. The ambrosia beetle and the fungus were likely introduced into the United States from Asia via solid wood packing material (Harrington et al. 2008). The unusual attraction of $X$. glabratus to healthy trees combined with its unique association with the $R$. lauricola and the highly virulent nature of this pathogen make it possible for a single infection to kill a healthy tree (Fraedrich et al. 2008). Since 2002, $X$. glabratus and laurel wilt disease have become established across the Atlantic coastal plains in South Carolina, Georgia, Florida, and Alabama (Bates et al. 2013; Fraedrich et al. 2008; Mayfield et al. 2008; Peña et al. 2012; Smith et al. 2009a, 2009b) and in recent years have spread into northern Louisiana (Fraedrich et al. 2015), Texas (Menard et al. 2016), and Arkansas (Olatinwo et al. 2016), threatening susceptible hosts across the southern forests.

\section{${ }^{\dagger}$ Corresponding author: R. Olatinwo; E-mail: rolatinwo@fs.fed.us}

The author(s) declare no conflict of interest.

This article is in the public domain and not copyrightable. It may be freely reprinted with customary crediting of the source. The American Phytopathological Society, 2019
Because of the rapidly expanding distribution of laurel wilt in the United States, the ecological impacts of the disease on forest ecosystems, and the economic impacts of this disease on avocado production, it is urgent and critical to explore potential control measures. Current disease management strategies for laurel wilt are very limited and generally ineffective for long-term management of the disease. Macro-infusion of redbay trees with the fungicide propiconazole can protect trees from laurel wilt for limited durations (Mayfield et al. 2008), making it essential to reinject trees every year or two. In commercial avocado groves, although the primary vector, $X$. glabratus, is uncommon (Carrillo et al. 2012; Menocal et al. 2018), laurel wilt can still spread via root transmission or lateral transfer by other ambrosia beetles (Carrillo et al. 2014; Ploetz et al. 2017). Although sanitation practices may help to limit disease spread in avocado orchards, these practices have not been effective in natural and urban forests (Hughes et al. 2015). The use of microorganisms to inhibit and control $R$. lauricola and $X$. glabratus has attracted some attention in recent years. Dunlap et al. (2017) found three Paenibacillus species and a Bacillus species were biologically active against $R$. lauricola, and Carrillo et al. (2015) demonstrated that an entomopathogenic fungus, Beauveria bassiana (Ascomycota: Hypocreales), was a potential biological control agent for $X$. glabratus.

During investigations of the fungal species associated with bark beetles from loblolly pine (Pinus taeda L.) in central Louisiana, an unknown fungus was discovered that exhibited broad-spectrum antifungal activities against many other fungi occurring in pine wood including species in the genera Ophiostoma, Fusarium, Pestalotiopsis, and Trichoderma (Olatinwo, unpublished). Preliminary investigations on the inhibitory properties of secondary metabolites 
from the unknown fungus led to our question of whether the fungus could exhibit similar fungistatic activity against $R$. lauricola. Hence, the primary goals of this study were (i) to identify the unknown fungus associated with the bark tissue of a loblolly pine, (ii) to evaluate possible inhibitory effect of the secondary metabolites produced by the fungus on the mycelial growth and spores germination of $R$. lauricola, and (iii) to determine efficacy of the secondary metabolites on $R$. lauricola in an in vivo experiment. This study is part of a larger effort to identify secondary metabolites with potent antifungal activity against $R$. lauricola that could be potentially useful within an integrated pest management program.

\section{Identification of Fungal Isolates with Inhibitory Activities}

The unidentified isolate (isolate R-8) was obtained during an investigation of fungal species associated with bark beetles from bolts of loblolly pine on the Kisatchie National Forest (Rapides Parish, LA) in October/November 2014. The isolate was maintained on potato dextrose agar (PDA) (39.0 g of PDA, EMD Chemical, Burlington, MA) and malt extract agar (MEA) (33.6 g of MEA, MP Biomedicals, Santa Ana, CA). Cultures of isolate R-8 consistently produced dense mycelium and noticeable darkpigmented secondary metabolites that diffused through both culture media and were often observed within 7 to 10 days (Fig. 1).

The identity of isolate R-8 was confirmed by polymerase chain reaction (PCR) amplification and analysis of the internal transcribed spacer (ITS) region from genomic DNA sample extracted from a 10-day-old culture grown on PDA. Extraction was conducted using the QIAGEN DNeasy Plant Tissue Mini extraction kit (QIAGEN, Valencia, CA) following the manufacturer's instructions, and the extracted DNA was stored at $-20^{\circ} \mathrm{C}$ and used as template in the PCR amplifications.

PCR amplification was performed in a $10-\mu 1$ reagent mixture contained $5 \mu \mathrm{l}$ of TopTaq PCR Master Mix (Qiagen), $1.5 \mu \mathrm{l}$ of a $5-\mu \mathrm{M}$ solution of the forward primer ITS1F (5'-CTTGGTCATTTAGAG GAAGTAA-3') (Gardes and Bruns 1993) and reverse primer ITS4R (5'-TCCTCCGCTTATTGATATGC-3') (White et al. 1990), $1 \mu \mathrm{l}$ of $10 \times$ CoralLoad, and $1 \mu \mathrm{l}$ of the DNA template, and amplification was performed using an Eppendorf Mastercycler Pro PCR machine. The amplification protocol consisted of initial denaturation at $95^{\circ} \mathrm{C}$ for 3 min, followed by 35 cycles of $35 \mathrm{~s}$ denaturation at $95^{\circ} \mathrm{C}, 55 \mathrm{~s}$ annealing at $58^{\circ} \mathrm{C}$, and $1 \mathrm{~min}$ extension at $72^{\circ} \mathrm{C}$, and a final extension at $72^{\circ} \mathrm{C}$ for $10 \mathrm{~min}$. Gel electrophoresis was performed to examine amplified products by loading $5 \mu$ l of PCR products on $1 \%$ agarose gels. The agarose was stained with ethidium bromide after $20 \mathrm{~min}$ of electrophoresis, and the resulting bands were visualized under ultraviolet illumination. PCR products were purified and sequenced at Genewiz (South Plainfield, NJ) (https://www.genewiz.com/).

The DNA sequence of the ITS region from isolate R-8 was compared with ITS sequences in GenBank (https://blast.ncbi.nlm.nih.gov/ Blast.cgi). Sixteen sequences (all available in GenBank) were included in multiple alignments and phylogenetic analysis (Table 1). Sequence alignments, editing, and analyses were conducted in MEGA 7.0 (Kumar et al. 2016). Molecular phylogenetic analysis and the evolutionary history was inferred by using the maximum likelihood method based on the Tamura-Nei model (Tamura and Nei 1993).

The sequenced ITS region from the unknown isolate R-8 (GenBank accession no. KT998902) and two other similar isolates, R-1 (GenBank accession no. KT998901) and R-10 (GenBank accession no. KT998903), found on loblolly pine bark had $98 \%$ similarity to Acaromyces ingoldii (GenBank accession no. NR07332, CBS 110050) that was originally isolated from citrus rust mites on grapefruit in Israel (Boekhout et al. 2003) (Table 1, Fig. 2).
To our knowledge, this would be the first known report of $A$. ingoldii isolates from loblolly pine.

Boekhout et al. (2003) described A. ingoldii as an anamorphic fungus, belonging phylogenetically to the Cryptobasidiaceae, Exobasidiomycetidae (Ustilaginomycetes, Basidiomycota) with septate hyphae, usually with the cytoplasm retracted in cells separated by lysed cells, and with sterigma-like outgrowths frequently occurring near the septa, giving rise to chains of fusiform blastoconidia. The fungus was further described as having thin aerial mycelium made up of blastoconidia, which gives the colony a velvety-pruinose appearance (Boekhout et al. 2003). Although A. ingoldii does not form blastoconidia in liquid media Sztejnberg et al. (2004), blastoconidia were obtainable when distilled water was added to Petri dishes with artificial media on which the fungus had developed.

Acaromyces is a monotypic yeast-like genus morphologically similar to "smut" fungi in the genera Pseudozyma and Meira (Exobasidiomycetes, Ustilaginomycotina), the latter of which is also associated with mites. Although phylogenetic analyses place Meria and Acaromyces within the Exobasidiales, Acaromyces spp. are placed in the family Cryptobasidiaceae, whereas Meria spp. are in the Brachybasidiaceae (Boekhout et al. 2003; Rush and Aime 2013).

\section{Inhibition of R. Iauricola Mycelial Growth}

Four $R$. lauricola isolates were used in the study. Two isolates (LA1 and LA2) were obtained from sapwood tissues of a sassafras tree with laurel wilt near Bernice, Louisiana, in 2014 (Fraedrich et al. 2015), one isolate (TX1) was collected from a redbay tree in 2015 near Lumberton, Texas (Menard et al. 2016), and an isolate (HH5) was collected from redbay in 2005 at Hilton Head, South Carolina (Fraedrich et al. 2008).

The inhibitory activity of $A$. ingoldii (isolate R-8) against $R$. lauricola isolates was evaluated on PDA and repeated on MEA assays in plastic Petri dishes (Fisherbrand; 9-cm diameter) in the laboratory. Three treatments were evaluated: (i) Raffaelea plated 7 days after isolate R-8 was inoculated with $50 \mu$ l of spore suspension $\left(\sim 2.0 \times 10^{4} \mathrm{CFU} / \mathrm{ml}\right)$ around the perimeter of the culture plate to allow inward diffusion of secondary metabolites into the agar (Fig. 1); (ii) Raffaelea agar plug plated simultaneously with isolate R-8 (no secondary metabolites secreted into the agar prior to pairing); and (iii) Raffaelea agar plug plated alone (control). Each treatment had four replicates. Assay plates were incubated at ambient temperature of $\sim 25^{\circ} \mathrm{C}$, and mycelial diameter growth for the $R$. lauricola isolates was measured and recorded daily for 2 weeks. The rate of mycelial growth for each of the four isolates was subsequently calculated. An analysis of variance (ANOVA) of the factorial experimental data and the mean comparison among treatments, isolates, and assay media using standard error of mean (SEM) were conducted in SAS-JMP version 11 (SAS, Cary, NC).

The mycelial growth of $A$. ingoldii was noticeably faster on PDA than MEA (Fig. 3), and production of secondary metabolites, observed as a dark-pigmented compound released into agar, was consistently observed on both MEA and PDA media at 10 to 15 days after inoculation. However, secondary metabolite production was initiated 2 to 3 days sooner on PDA compared with MEA, perhaps owing to differences in the nutrient composition of the two media. The rate of $R$. lauricola mycelial growth differed among the three treatments evaluated on the two culture media (MEA and PDA); however, the pattern of mycelial growth responses to treatments was consistent for all four $R$. lauricola isolates (Fig. 3, Tables 2 and 3). Compared with other treatments, mycelial 
growth for all $R$. lauricola isolates was completely inhibited on PDA and significantly reduced on MEA when secondary metabolites of $A$. ingoldii were present in the agar at the time that the fungi were plated (treatment A; Fig. 3). Among the R. lauricola isolates, growth of HH5 (interestingly, the oldest isolate) was faster than the three other $R$. lauricola isolates, whereas isolate TX1 was slightly slower than isolates LA1 and LA2 (Fig. 3). Results showed the same pattern of inhibitory activity was observed among all isolates
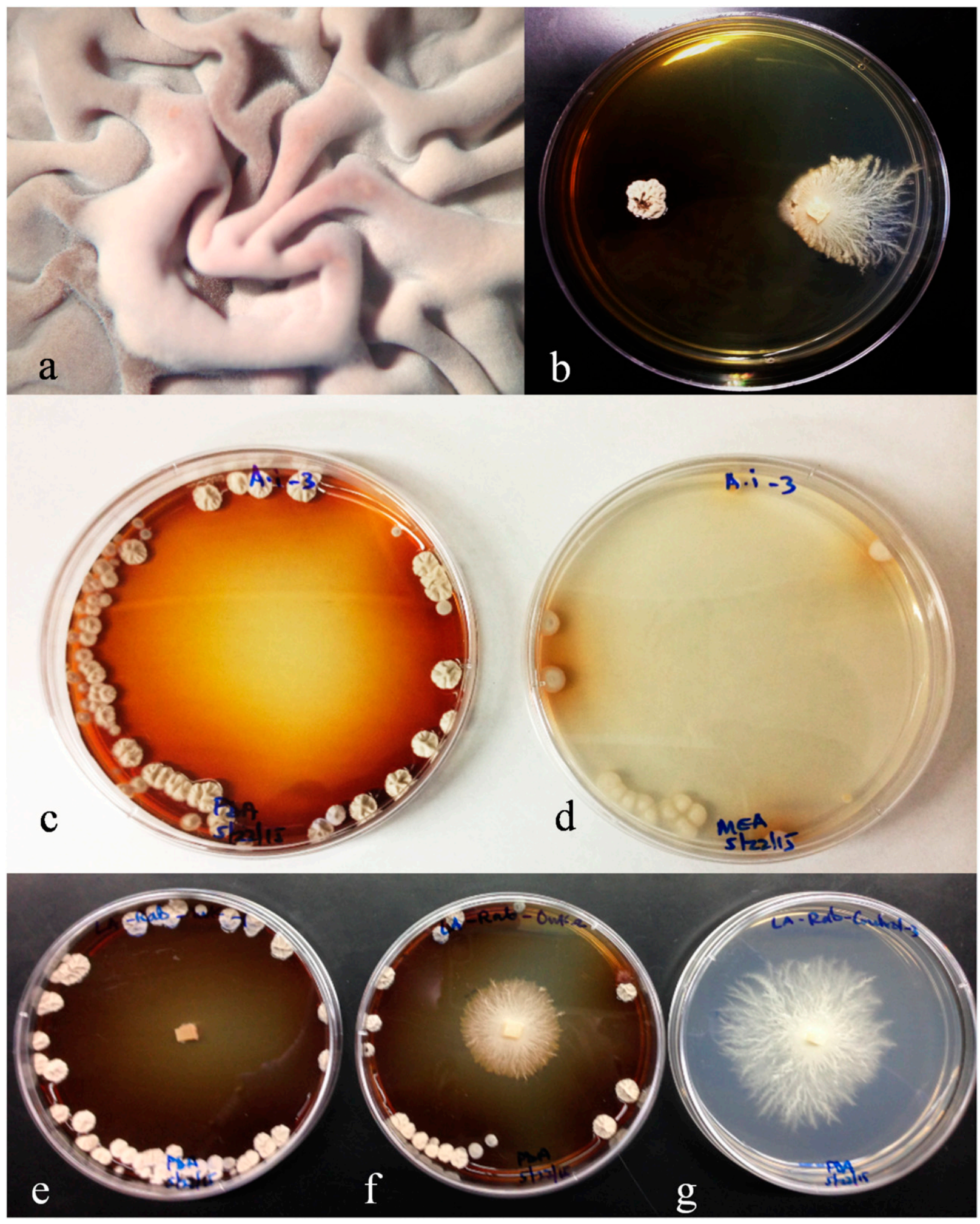

\section{FIGURE 1}

a, A culture of Acaromyces ingoldii (isolate R-8) mycelium observed under the dissecting microscope; $\mathbf{b}$, inhibition of Raffaelea lauricola isolate by A. ingoldii secondary metabolites on potato dextrose agar (PDA); c, brown discoloration in PDA associated with diffusion of secondary metabolites from A. ingoldii on the PDA; d, growth of $A$. ingoldii and associated discoloration on malt extract agar; e, complete inhibition of R. lauricola (isolate LA) plated on PDA 7 days after $A$. ingoldii. f, partial inhibition of $R$. lauricola plated simultaneously with $A$. ingoldii on PDA; and $\mathbf{g}$, $R$. lauricola isolate LA without $A$. ingoldii on a PDA. 
(i.e., no growth of $R$. lauricola on PDA when A. ingoldii is previously established; reduced growth on PDA when $R$. lauricola and $X$. ingoldii are established at the same time). On MEA, $R$. lauricola isolates show reduced growth when $A$. ingoldii is previously established but no reduction in growth when $R$. lauricola and $A$. ingoldii are established at the same time (Tables 2 and 3).

There was no indication of direct competition between $A$. ingoldii and $R$. lauricola isolates when the fungi were plated simultaneously (treatment B); however, subsequent secondary metabolite production and diffusion through the agar significantly reduced the rate of mycelial growth (fungistatic effect) of all $R$. lauricola isolates on PDA. Plating $A$. ingoldii and $R$. lauricola simultaneously on MEA had no subsequent effect on mycelial growth of $R$. lauricola (Table 3). Secondary metabolites produced by A. ingoldii consistently and significantly reduced mycelial growth of $R$. lauricola with complete inhibition of mycelial growth on PDA. Initial $R$. lauricola mycelial growth on MEA was subsequently halted after 2 to 3 days owing to the fungistatic effect of secondary metabolites released into the agar by the $A$. ingoldii (Table 3 ).

\section{Inhibition of $\boldsymbol{R}$. lauricola Spore Germination}

The effect of $A$. ingoldii (isolate R-8) secondary metabolites on the germination of $R$. lauricola spores was evaluated using different concentrations of crude extract obtained from liquid culture prepared by dissolving $2.4 \mathrm{~g}$ of potato dextrose broth (PDB) (Sigma-Aldrich, St. Louis, MO) in $100 \mathrm{ml}$ of sterile deionized water in a 250-ml Pyrex Erlenmeyer flask (Pyrex, Greencastle, PA ). Autoclaved PDB mixture was allowed to cool for 2 to $3 \mathrm{~h}$ and then inoculated with isolate R-8 agar plug. The culture was incubated at room temperature $\left(\sim 25^{\circ} \mathrm{C}\right)$ for 28 days, after which crude extract was decanted into sterile $15-\mathrm{ml}$ conical tubes (Falcon Becton Dickson, Franklin Lakes, NJ) and centrifuged at $3,000 \times g$ for $5 \mathrm{~min}$. The supernatant was filtered using the Millex GP $0.22 \mu \mathrm{m}$ syringe filter (Millipore, Carrigtwohill, Ireland) to eliminate any remaining suspended spores. For the spore germination test, five concentrations $(100,10,1,0.1$, and $0 \%$ ) of extract was obtained by serial dilution of filtrate with PDB in a sterile 96-well culture plate (Eppendorf AG, Hamburg, Germany). Sixteen replicates of each concentration (100- $\mu$ l volume per well) were inoculated individually with $10 \mu$ l of $R$. lauricola (TX1) spore suspension. The assay plate was incubated at room temperature, and spore germination was evaluated after $72 \mathrm{~h}$.

Direct exposure of $R$. lauricola spores to $10 \%$ or higher concentrations of $A$. ingoldii crude extracts resulted in complete

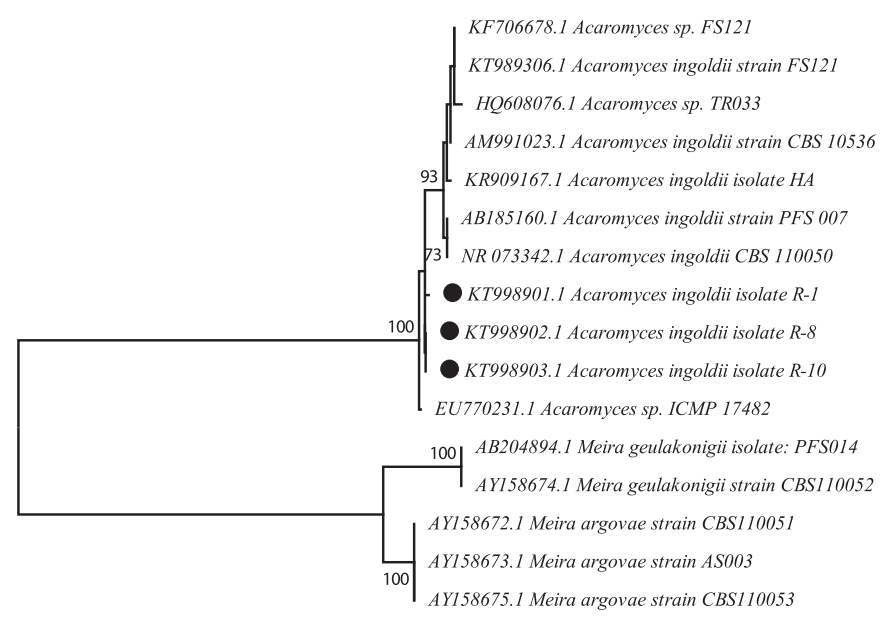

FIGURE 2

Molecular phylogenetic analysis by the maximum likelihood method. The evolutionary history was inferred by using the maximum likelihood method based on the Tamura-Nei model (Tamura and Nei 1993). The tree with the highest log likelihood $(-1,252.7)$ is shown. The percentage of trees in which the associated taxa clustered together is shown next to the branches. Initial tree(s) for the heuristic search were obtained automatically by applying the Neighbor-Join and BioNJ algorithms to a matrix of pairwise distances estimated using the maximum composite likelihood approach and then selecting the topology with superior log likelihood value. The tree was drawn with branch lengths measured in the number of substitutions per site. The analysis involved 16 nucleotide sequences. All positions with less than $95 \%$ site coverage were eliminated. That is, fewer than $5 \%$ alignment gaps, missing data, and ambiguous bases were allowed at any position. There was a total of 431 positions in the final dataset. Evolutionary analyses were conducted in MEGA 7 (Kumar et al. 2016).

TABLE 1

\begin{tabular}{llll}
\multicolumn{1}{l}{ Internal transcribed spacer (ITS) region sequences included in the phylogenetic analysis of the Acaromyces ingoldii isolate R-8 and } \\
closely related sequences in GenBank
\end{tabular}


inhibition of $R$. lauricola spore germination and hyphae growth in culture plate assays, whereas spore germination and hyphae growth were observed at concentrations between 0 and $1 \%$ (Fig. 4).
Efficacy Against R. lauricola on Redbay Seedlings

The effect of different concentrations of $A$. ingoldii secondary metabolites extract on $R$. lauricola was evaluated on redbay seedlings in a growth chamber experiment (Fig. 5). Six treatments

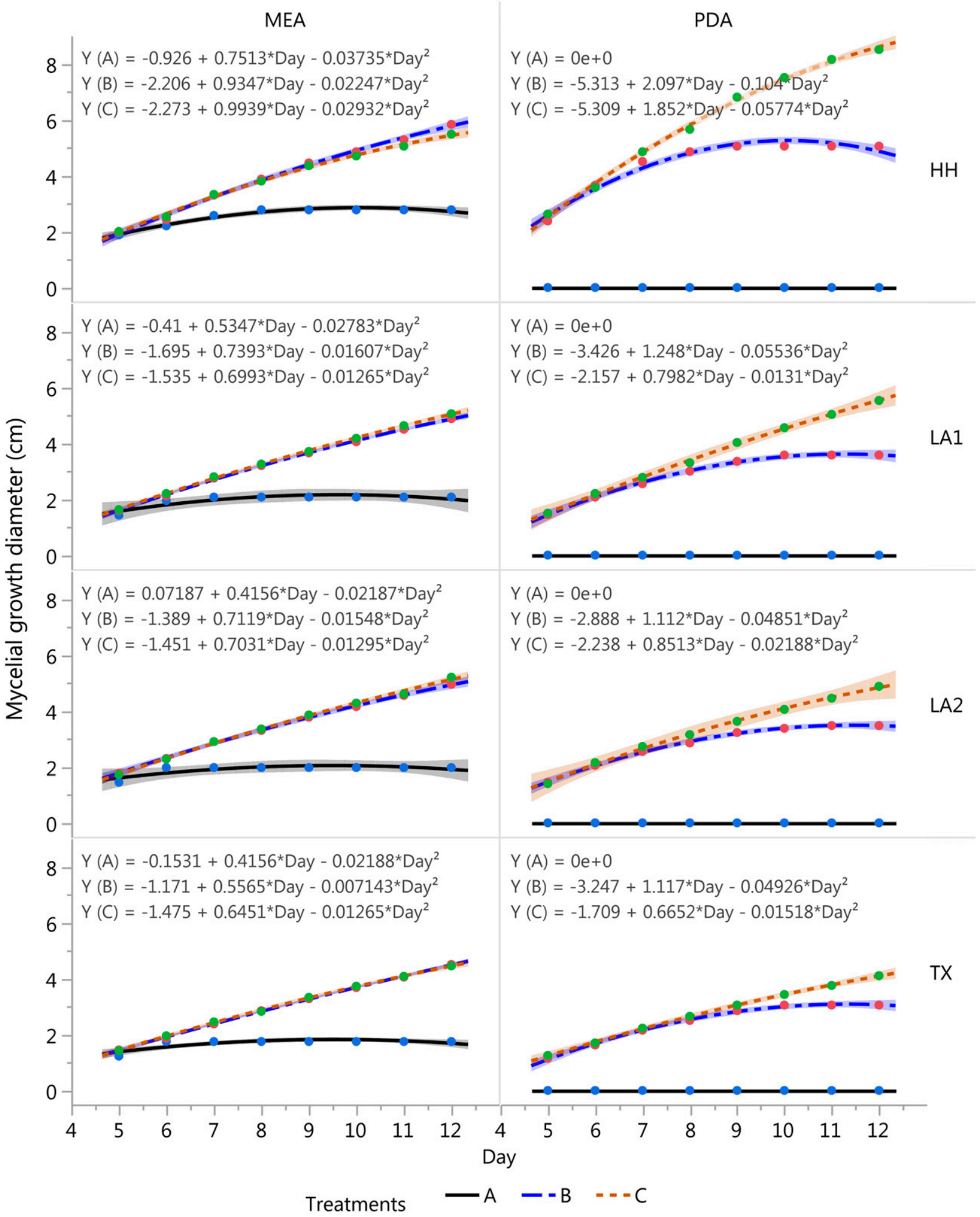

FIGURE 3

Acaromyces ingoldii treatment effects on the rate of mycelial growth of four Raffaelea lauricola isolates on malt extract agar and potato dextrose agar. Treatment $\mathrm{A}=A$. ingoldii established in plate margins 7 days prior to inoculation of plates with $R$. lauricola; treatment $\mathrm{B}=$ plates simultaneously inoculated with $A$. ingoldii and $R$. lauricola; and treatment $\mathrm{C}=$ plates inoculated only with $R$. lauricola. 
evaluated were (a) inoculation with only $R$. lauricola spores suspended in sterile water $(\mathrm{RL}+0 \%)$, (b) inoculation with $R$. lauricola spores suspended in $10 \%$ extract (RL $+10 \%)$, (c) inoculation with $R$. lauricola spores suspended in $20 \%$ extract (RL $+20 \%)$, (d) inoculation with only sterile water (control), (e) inoculation with $10 \%$ extract, and (f) inoculation with $20 \%$ extract. Each treatment had four replicates, and the $R$. lauricola spore concentration used for inoculation was $20 \mu \mathrm{l}$ of spore suspension $\left(\sim 1.0 \times 10^{5} \mathrm{CFU}\right)$. The evaluation of laurel wilt symptoms on redbay seedlings was conducted by visual assessment 6 weeks postinoculation, based on four symptom categories: (i) no symptoms, (ii) chlorotic leaves, (iii) partial wilt of plants involving one or more branches, and (iv) total wilt of plants. The number of seedlings exhibiting symptoms per treatment was recorded and compared across the six treatments.

Results showed that redbay seedlings inoculated with $R$. lauricola spores suspended in $10 \%$ or $20 \%$ solutions of the A. ingoldii secondary metabolites did not prevent the development of laurel wilt in redbay plants. After 6 weeks, three out of four redbay seedlings inoculated with only $R$. lauricola $(\mathrm{RL}+0 \%)$ wilted, and the fourth seedling developed noticeable symptoms including chlorotic leaves and wilting in lower branches. All four redbay seedlings inoculated with $R$. lauricola spores suspended in $10 \% \mathrm{~A}$. ingoldii extract $(\mathrm{RL}+10 \%)$ were symptomatic and completely wilted after 6 weeks, but only two of four seedlings inoculated with $R$. lauricola spores suspended in $20 \%$ A. ingoldii extract $(\mathrm{RL}+$ $20 \%$ ) wilted, and the remaining two seedlings had very mild symptoms. These results suggest that that higher concentration of the extract (i.e., 20\%) was better than lower concentration (10\%); however, both concentrations were not lethal to $R$. lauricola and offered no significant long-term protections to seedlings evaluated in this study.

Fungistatic effects of the extract against $R$. lauricola spores that were observed during in vitro tests were not observed when $R$. lauricola with extracts were inoculated into seedlings, suggesting that $R$. lauricola can overcome any initial inhibition and still kill a plant. The extract dosage and mode of application may have been inadequate for several reasons, including further dilution of the extract within the xylem that provided a less than optimal concentration as spores moved beyond the inoculation point or the possible loss of potency of the extract within the host over time. These factors could have rendered the $A$. ingoldii crude extract to be less effective against $R$. lauricola for inhibition to occur. However, the results also demonstrate the resilience of $R$. lauricola as a pathogen, indicating a consistent and considerable level of exposure to a potent active ingredient would be needed to prevent infection and laurel wilt disease establishment.

It is possible that a prophylactic treatment of redbay seedlings with live $A$. ingoldii spores several weeks ahead of a $R$. lauricola infection could offer an enduring protection as opposed to a single application of extract. In fact, the use of $A$. ingoldii, an endophytic fungal antagonist, may be more effective as a biocontrol agent through natural production of metabolites as it grows within the host tissue in response to an intruding $R$. lauricola pathogen. Hence, additional studies will be required to examine the best approach to

\begin{tabular}{|c|c|c|c|}
\hline \multicolumn{4}{|c|}{$\begin{array}{l}\text { TABLE } 3 \\
\text { Effect of Acaromyces ingoldii treatments on mycelial growth } \\
\text { of four Raffaelea lauricola isolates on malt extract agar (MEA) } \\
\text { and potato dextrose agar (PDA) after } 12 \text { days }\end{array}$} \\
\hline Isolate & Treatmenty & $\begin{array}{l}\text { Growth on MEA, } \\
\text { mean } \pm \text { SEM }(\mathrm{cm})^{z}\end{array}$ & $\begin{array}{l}\text { Growth on PDA, } \\
\text { mean } \pm \text { SEM }(\mathbf{c m})^{z}\end{array}$ \\
\hline \multirow[t]{3}{*}{ HH5 } & A & $2.8 \pm 0.1 \mathrm{a}$ & $0.0 \pm 0.0 \mathrm{a}$ \\
\hline & B & $5.8 \pm 0.2 b$ & $5.1 \pm 0.1 \mathrm{~b}$ \\
\hline & $\mathrm{C}$ & $5.5 \pm 0.1 b$ & $8.5 \pm 0.0 \mathrm{c}$ \\
\hline \multirow[t]{3}{*}{ LA1 } & A & $2.1 \pm 0.2 \mathrm{a}$ & $0.0 \pm 0.0 \mathrm{a}$ \\
\hline & B & $4.9 \pm 0.1 b$ & $3.6 \pm 0.1 b$ \\
\hline & $\mathrm{C}$ & $5.1 \pm 0.1 \mathrm{~b}$ & $5.5 \pm 0.3 \mathrm{c}$ \\
\hline \multirow[t]{3}{*}{ LA2 } & A & $2.0 \pm 0.2 \mathrm{a}$ & $0.0 \pm 0.0 \mathrm{a}$ \\
\hline & B & $5.0 \pm 0.2 b$ & $3.5 \pm 0.1 b$ \\
\hline & $\mathrm{C}$ & $5.2 \pm 0.1 b$ & $4.9 \pm 0.4 \mathrm{c}$ \\
\hline \multirow[t]{3}{*}{ TX1 } & A & $1.8 \pm 0.1 \mathrm{a}$ & $0.0 \pm 0.0 \mathrm{a}$ \\
\hline & B & $4.5 \pm 0.0 \mathrm{~b}$ & $3.1 \pm 0.1 b$ \\
\hline & $\mathrm{C}$ & $4.5 \pm 0.1 \mathrm{~b}$ & $4.1 \pm 0.2 \mathrm{c}$ \\
\hline
\end{tabular}

${ }^{\mathrm{y}}$ Treatments: $\mathrm{A}=R$. lauricola plated 7 days after $A$. ingoldii (isolate R-8) was inoculated with $50 \mu \mathrm{l}$ of spore suspension $\left(\sim 2.0 \times 10^{4} \mathrm{CFU} / \mathrm{ml}\right)$ around the perimeter of the culture plate to allow inward diffusion of secondary metabolites into the agar; $\mathrm{B}=R$. lauricola agar plug plated simultaneously with $A$. ingoldii (no secondary metabolites secreted into the agar prior to pairing); and $\mathrm{C}=R$. lauricola agar plug plated alone (control). Each treatment had four replicates.

${ }^{\mathrm{z}}$ Mean and standard error of mean (SEM) not followed by same letter are significantly different within column (i.e., within medium type).

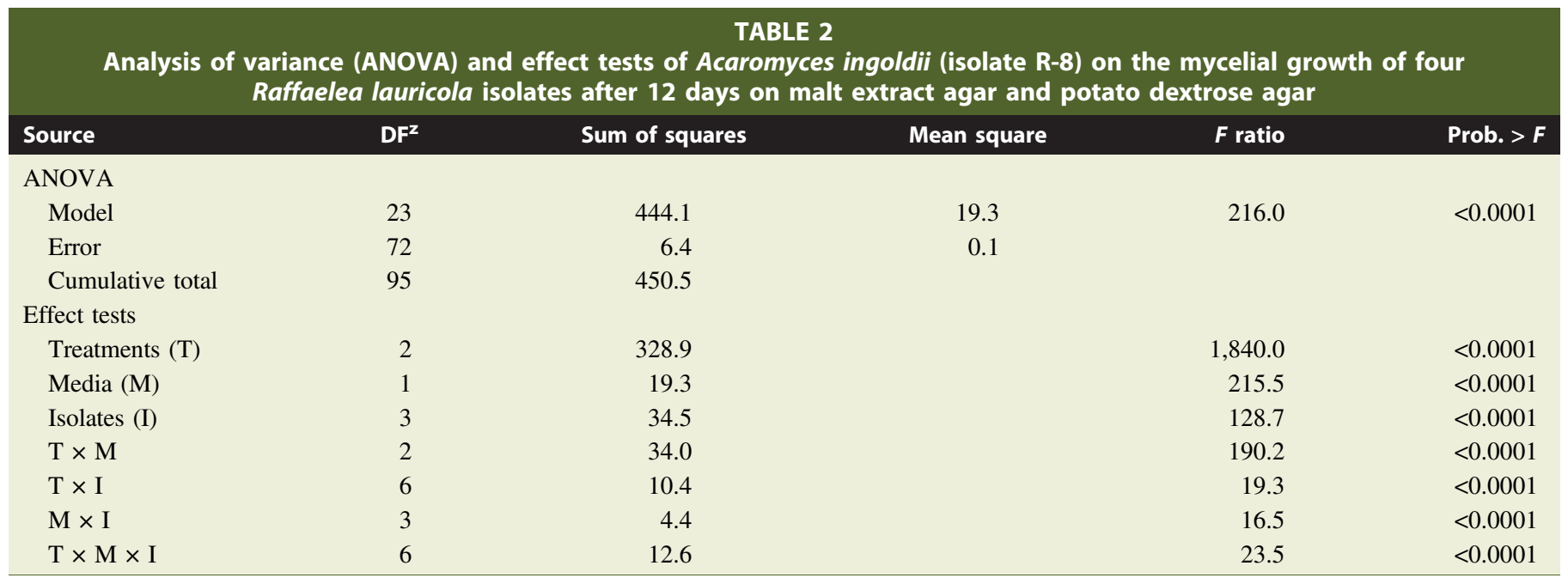

${ }^{\mathrm{z}} \mathrm{DF}=$ degrees of freedom. 
optimize the efficacy of $A$. ingoldii in future greenhouse and field application experiments.

\section{Potential Application in Disease Management}

Findings from this study suggest potential uses for the secondary metabolites produced by $A$. ingoldii against $R$. lauricola, the cause of laurel wilt. Previous observations, along with the results from the current study, highlight the importance of secondary metabolites associated with Acaromyces species on other organisms. We observed that secondary metabolites produced by A. ingoldii (isolate R-8) consistently and significantly reduced the mycelial growth of $R$. lauricola isolates. We also observed $100 \%$ mycelial growth inhibition in all four $R$. lauricola isolates evaluated against R-8 secondary metabolites on PDA and found a significant reduction in the mycelial growth of the four isolates on MEA after 12 days, when $R$. lauricola was plated 7 days after $A$. ingoldii (isolate R-8) was inoculated. Faster production of secondary metabolites on PDA than MEA most likely accounted for the early inhibition of mycelial growth on PDA. The rapid mycelial growth of $R$. lauricola that was initially noted on MEA was subsequently halted after 2 to 3 days owing to lagging fungistatic effects of secondary metabolites being produced by the Acaromyces isolate R- 8 . Direct competition between $A$. ingoldii and $R$. lauricola was minimal on PDA and absent MEA.

A. ingoldii has been reported across diverse habitats and environments worldwide (Table 1). In fact, the isolate evaluated in the current study was discovered from a loblolly pine bolt during assessments of fungi associated with bark beetles, suggesting $A$.

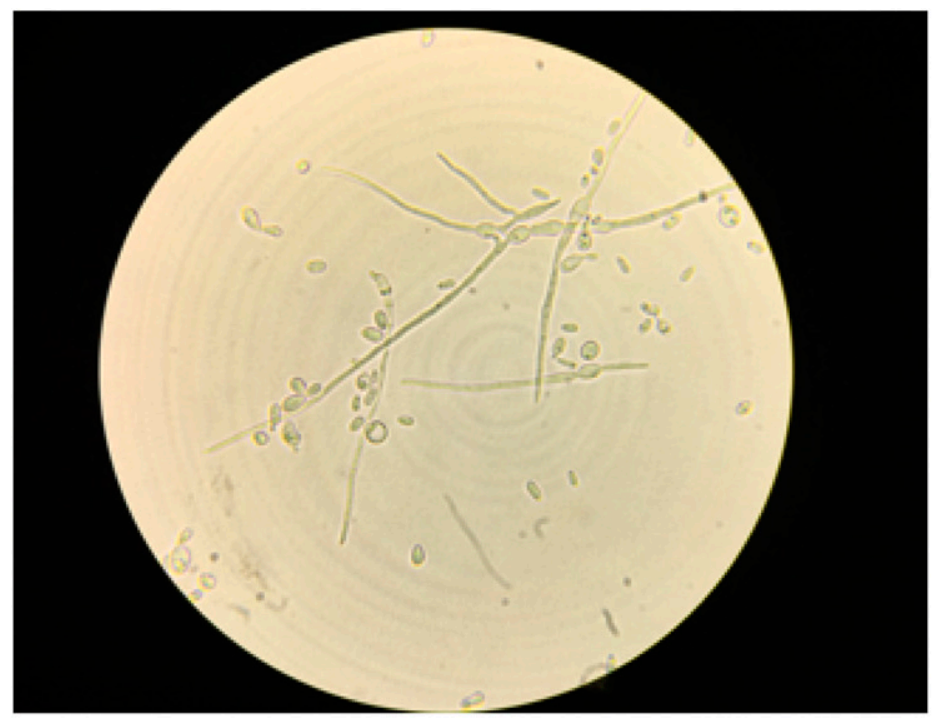

$0 \%$

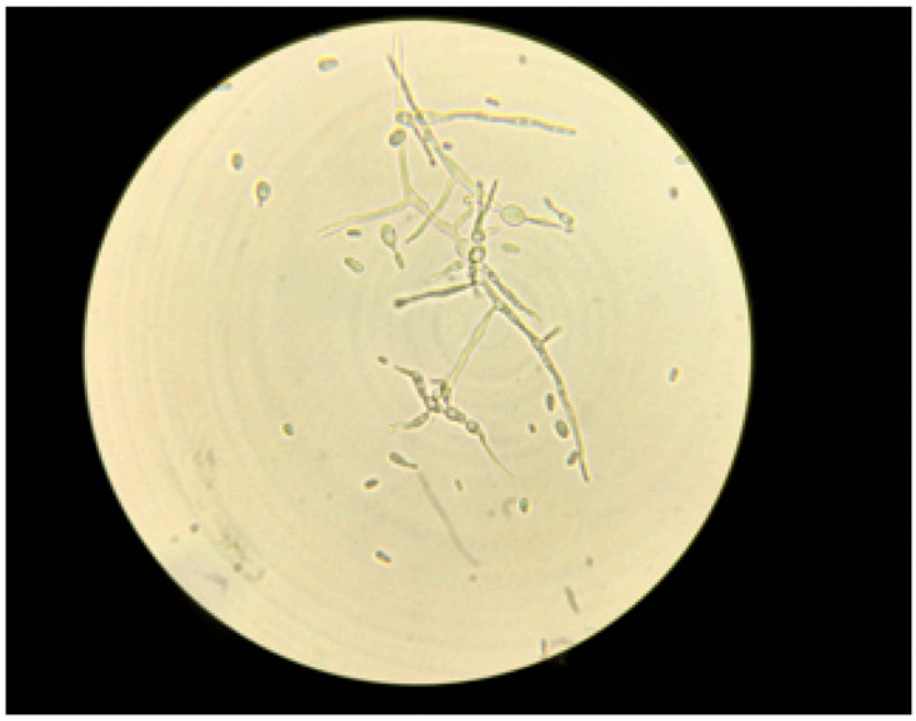

$1 \%$

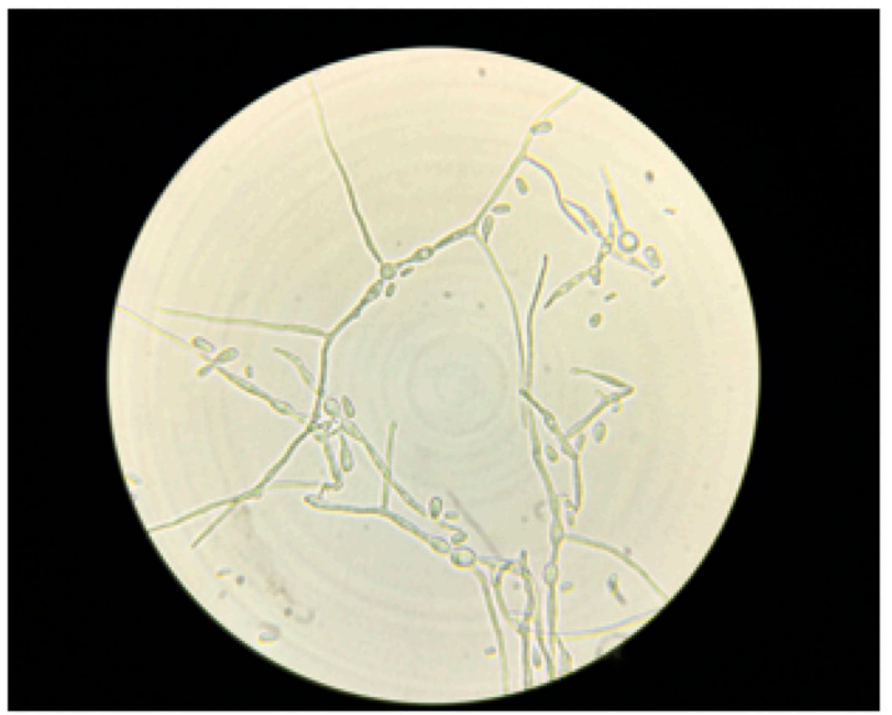

$0.10 \%$

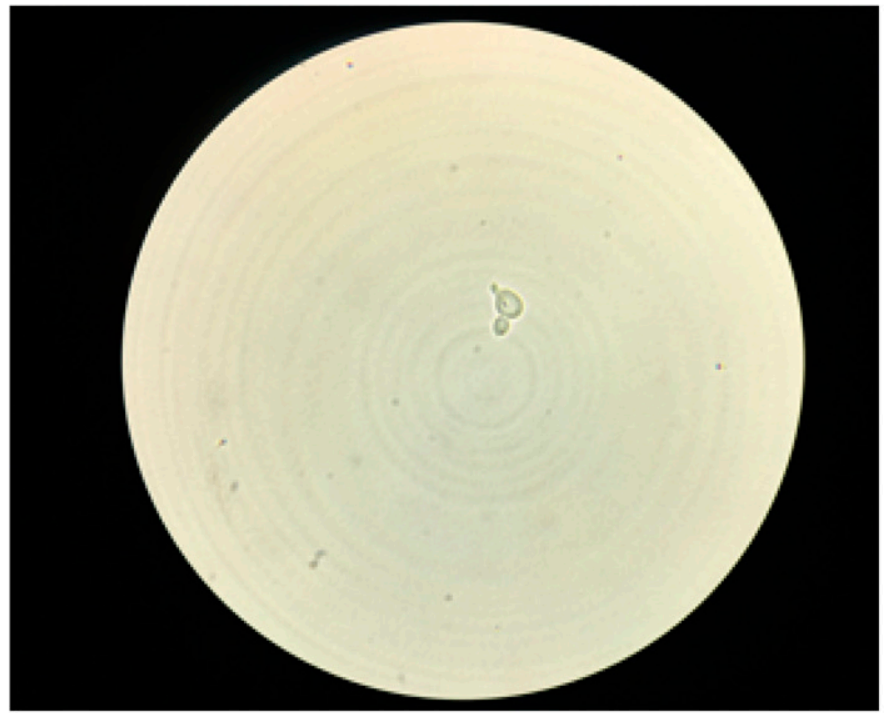

$10 \%$

\section{FIGURE 4}

Microscopic assessments of the effect of varying concentrations of Acaromyces ingoldii crude extract (0 to 100\%) on spore germination of Raffaelea lauricola (isolate TX1) after 72-h incubation in a 96-well culture plate. No spore germination was found in the crude extract at 10 and $100 \%$ concentrations. 
ingoldii could be associated with galleries of bark beetles that colonize southern pines, a new niche for $A$. ingoldii that has never been reported. Is the fungus protecting the beetles from mites, or could the fungus be detrimental to the beetles? Currently, the role the fungus might be playing is unclear; hence, further investigation would be needed. Interestingly, the fungus has been also isolated from nesting cavities of the red-cockaded woodpecker (RCW; Leuconotopicus borealis Vieillot), an endangered bird species in the southeastern United States that specializes in excavating cavities into the heartwood of living pines. Jusino et al. (2015) found that cavities being excavated by RCWs have shown distinct fungal communities that commonly include A. ingoldii, which may be beneficial to the woodpeckers by parasitizing mites or inhibiting fungi that could be detrimental to the RCW.
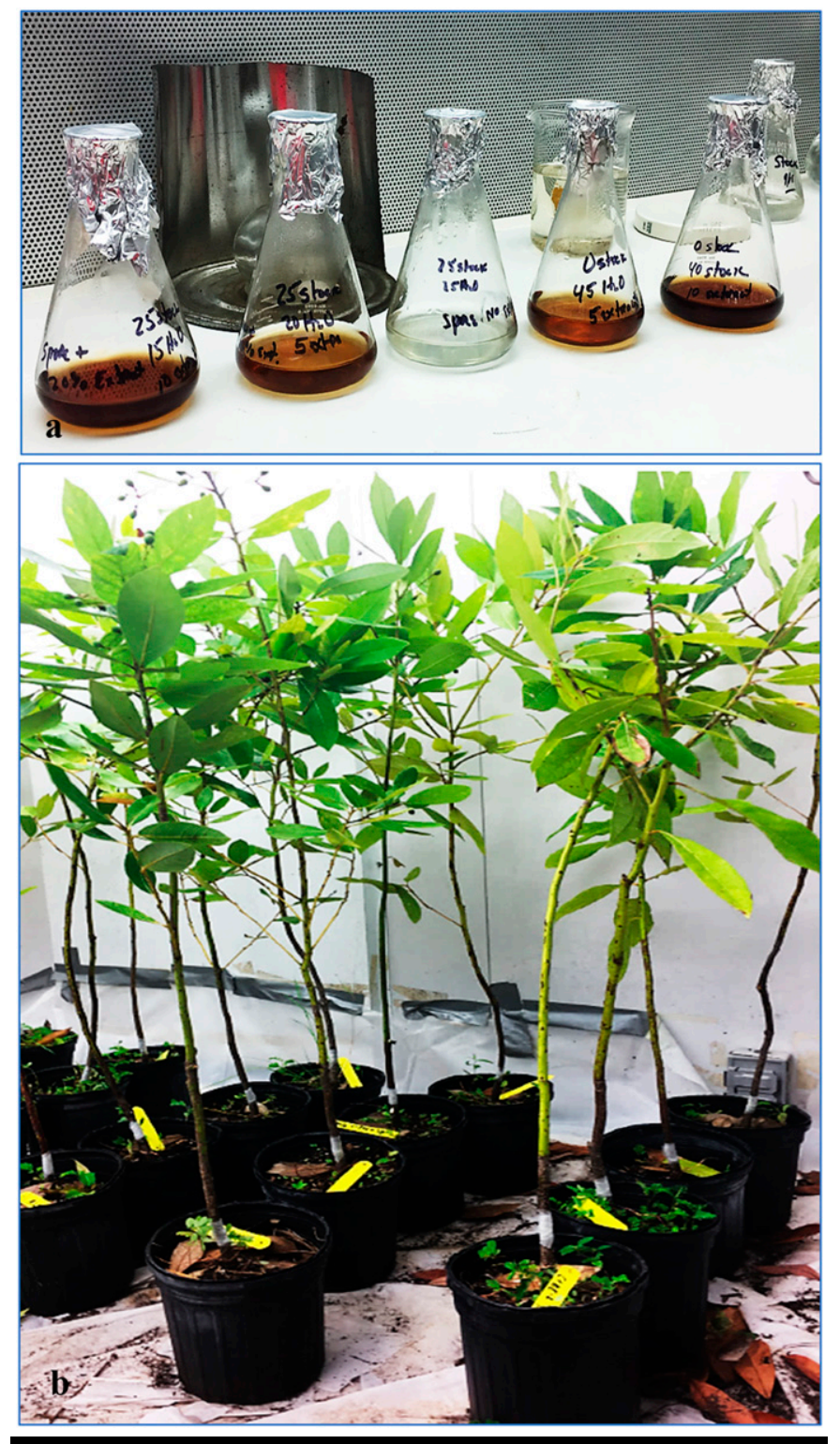

FIGURE 5

a, Raffaelea lauricola spores suspended in different concentrations of Acaromyces ingoldii (isolate R-8) secondary metabolites crude extract; and $\mathbf{b}$, some redbay seedlings inoculated with $R$. lauricola spores in the growth chamber.
Historically, Acaromyces species have been thought to be pathogens of various mite species. Bekker (1940) described Acaromyces glycyphagi as a parasite of the mite Glycyphagus destructor (Schrank), and it was associated with a high rate of mite mortality. Boekhout et al. (2003) reported a high mortality rate among several mite species after inoculation with $A$. ingoldii. Subsequent studies (Gerson et al. 2008; Paz et al. 2007) confirmed that A. ingoldii possessed potent biocontrol capabilities against mite species and showed that toxic chemicals secreted by the fungus were lethal to mites. Paz et al. (2007) also found A. ingoldii, and two other fungi, Meira geulakonigii and Meira argovae, caused high mortality in five herbivorous mite species within 1 to 2 weeks after application.

A. ingoldii has been found to inhibit the growth of other phytopathogenic fungi, and it was suggested that competition for hydrocarbons could be responsible for the inhibitory activity, although the antagonistic effect exhibited by $A$. ingoldii against mites and fungi has also been attributed to secreted toxins, as confirmed by exposing sclerotia of Sclerotinia sclerotiorum and S. rolfsii to crude extracts of the fungus (Gerson et al. 2005; Kushnir et al. 2011; Sztejnberg et al. 2004). A. ingoldii was associated with pears in Japan, where it was reported to be causing a stain in immature fruit (Yasuda et al. 2005); however, there was no indication that the fungus was responsible for any damage. The fungus has been also associated with other fruit tree crops in France (Travadon et al. 2016), Israel (Boekhout et al. 2003), New Zealand (https://www.ncbi.nlm.nih.gov/nuccore/EU770231), and Vietnam (https://www.ncbi.nlm.nih.gov/nuccore/AM991023) and was found in marine sediment in the South China Sea (Gao et al. 2016). One could argue that with its ability to establish in such diverse habitats and with its unique inhibitory properties as observed, A. ingoldii might potentially be a good biocontrol agent.

The preliminary analysis of secondary metabolites from $A$. ingoldii in the current study yielded cryptosporin, coryoctalactone $\mathrm{D}$, and a third compound similar to cryptosporin not yet fully identified (Olatinwo, unpublished). Gao et al. (2016) showed that secondary metabolites from some $A$. ingoldii isolates have yielded a new naphtha-[2,3-b] pyrandione analog, acaromycin A, and a new thiazole analog, acaromyester A, as well as the previously known compound (+)-cryptosporin. Interestingly, studies with these metabolites have shown they have significant activities against tumor cells (Gao et al. 2016).

The current study represents a preliminary effort to identify microorganisms with natural antifungal compounds with fungicidal/ fungistatic activities against $R$. lauricola, which could be potentially useful as part of integrated management program to limit further spread of laurel wilt. The fungistatic effect of A. ingoldii demonstrated in this study and on a broad range of fungi observed in the laboratory (Olatinwo, unpublished) suggest the secondary metabolites present in the crude extracts may have potential utility in managing $R$. lauricola and perhaps laurel wilt disease in high-value susceptible host tree species such as in commercial avocado groves in California and Florida. At this point, successful application strategies and tactics using the secondary metabolites are unknown and will depend on many factors. Further investigation will be needed to characterize specific composition of the $A$. ingoldii secondary metabolites and to examine the efficacy, specificity, effective deployment methods, and other potential benefits that the Acaromyces species may offer for potential disease management.

\section{Acknowledgments}

The authors thank Wood Johnson (USDA Forest Health Protection, Pineville, LA) for assistance with locating infected sassafras with laurel wilt and fungal isolates in Louisiana. 


\section{Literature Cited}

Bates, C. A., Fraedrich, S. W., Harrington, T. C., Cameron, R. S., Menard, R. D., and Best, G. S. 2013. First report of laurel wilt, caused by Raffaelea lauricola, on sassafras (Sassafras albidum) in Alabama. Plant Dis. 97:688.

Bekker, E. G. 1940. Acaromyces glycyphagi gen. et sp. n., a parasite of the mite, Glycyphagus destructor, Schrank. Uchenye Zapiski mosk. gosud. Univ. Zool. 42:113-128.

Boekhout, T., Theelen, B., Houbraken, J., Robert, V., Scorozetti, G., Gafni, A., Gerson, U., and Sztejnberg, A. 2003. Novel anamorphic mite-associated fungi belonging to the Ustilaginomycetes: Meira geulakonigii gen. nov., sp. nov., Meira argovae sp. nov. and Acaromyces ingoldii gen. nov., sp. nov. Int. J. Syst. Evol. Microbiol. 53:1655-1664.

Carrillo, D., Duncan, R. E., and Peña, J. E. 2012. Ambrosia beetles (Coleoptera: Curculionidae: Scolytinae) that breed in avocado wood in Florida. Fla. Entomol. 95:573-579.

Carrillo, D., Duncan, R. E., Ploetz, J. N., Campbell, A. F., Ploetz, R. C., and Peña, J. E. 2014. Lateral transfer of a phytopathogenic symbiont among native and exotic ambrosia beetles. Plant Pathol. 63:54-62.

Carrillo, D., Dunlap, C. A., Avery, P. B., Navarrete, J., Duncan, R. E., Jackson, M. A., Behle, R. W., Cave, R. D., Crane, J., Rooney, A. P., and Peña, J. E. 2015. Entomopathogenic fungi as biological control agents for the vector of the laurel wilt disease, the redbay ambrosia beetle, Xyleborus glabratus (Coleoptera: Curculionidae). Biol. Control 81:44-50.

Dunlap, C. A., Lueschow, S., Carrillo, D., and Rooney, A. P. 2017. Screening of bacteria for antagonistic activity against phytopathogens of avocados. Plant Gene 11:17-22.

Fraedrich, S. W., Harrington, T. C., Rabaglia, R. J., Ulyshen, M. D., Mayfield Iii, A. E., Hanula, J. L., Eickwort, J. M., and Miller, D. R. 2008. A fungal symbiont of the redbay ambrosia beetle causes a lethal wilt in redbay and other Lauraceae in the southeastern United States. Plant Dis. 92:215-224.

Fraedrich, S. W., Johnson, C. W., Menard, R. D., Harrington, T. C., Olatinwo, R., and Best, G. S. 2015. First report of Xyleborus glabratus (Coleoptera: Curculionidae: Scolytinae) and laurel wilt in Louisiana, USA: The disease continues westward on sassafras. Fla. Entomol. 98:1266-1268.

Gao, X. W., Liu, H. X., Sun, Z. H., Chen, Y. C., Tan, Y. Z., and Zhang, W. M. 2016. Secondary metabolites from the deep-sea derived fungus Acaromyces ingoldii FS121. Molecules 21:371.

Gardes, M., and Bruns, T. D. 1993. ITS primers with enhanced specificity for basidiomycetes-Application to the identification of mycorrhizae and rusts. Mol. Ecol. 2:113-118.

Gerson, U., Gafni, A., Paz, Z., and Sztejnberg, A. 2008. A tale of three acaropathogenic fungi in Israel: Hirsutella, Meira and Acaromyces. Exp. Appl. Acarol. 46:183-194

Gerson, U., Paz, Z., Kushnir, L., and Sztejnberg, A. 2005. New fungi to control phytophagous mites and phytopathogenic fungi. IOBC WPRS Bull. 28:103-106.

Harrington, T. C., Fraedrich, S. W., and Aghayeva, D. N. 2008. Raffaelea lauricola, a new ambrosia beetle symbiont and pathogen on the Lauraceae. Mycotaxon 104:399-404.

Hughes, M. A., Smith, J. A., Ploetz, R. C., Kendra, P. E., Mayfield, A. E., Hanula, J., Hulcr, J., Stelinski, L., Cameron, S., Riggins, J. J., Carrillo, D., Rabaglia, R., and Eickwort, J. 2015. Recovery plan for laurel wilt on redbay and other forest species caused by Raffaelea lauricola and disseminated by Xyleborus glabratus. Plant Health Prog. 16:173-210.

Jusino, M. A., Lindner, D. L., Banik, M. T., and Walters, J. R. 2015. Heart rot hotel: Fungal communities in red-cockaded woodpecker excavations. Fungal Ecol. 14:33-43.
Kumar, S., Stecher, G., and Tamura, K. 2016. MEGA7: Molecular Evolutionary Genetics Analysis version 7.0 for bigger datasets. Mol. Biol. Evol. 33: 1870-1874.

Kushnir, L., Paz, Z., Gerson, U., and Sztejnberg, A. 2011. The effect of three basidiomycetous fungal species on soil-borne, foliage and fruit-damaging phytopathogens in laboratory experiments. BioControl 56:799-810.

Mayfield, A. E., Smith, J. A., Hughes, M., and Dreaden, T. J. 2008. First report of laurel wilt disease caused by a Raffaelea sp. on avocado in Florida. Plant Dis. 92:976.

Menard, R. D., Clarke, S. R., Fraedrich, S. W., and Harrington, T. C. 2016. First report of laurel wilt, caused by Raffaelea lauricola, on redbay (Persea borbonia) in Texas. Plant Dis. 100:1502.

Menocal, O., Kendra, P. E., Montgomery, W. S., Crane, J. H., and Carrillo, D. 2018. Vertical distribution and daily flight periodicity of ambrosia beetles (Coleoptera: Curculionidae) in Florida avocado orchards affected by laurel wilt. J. Econ. Entomol. 111:1190-1196.

Olatinwo, R., Barton, C., Fraedrich, S., Johnson, W., and Hwang, J. 2016. First report of laurel wilt, caused by Raffaelea lauricola, on sassafras (Sassafras albidum) in Arkansas. Plant Dis. 100:2331.

Paz, Z., Gerson, U., and Sztejnberg, A. 2007. Assaying three new fungi against citrus mites in the laboratory, and a field trial. BioControl 52:855-862.

Peña, P. E., Carrillo, D., Duncan, R. E., Capinera, J. L., Brar, G., McLean, S., Arpaia, M. L., Focht, E., Smith, J. A., Hughes, M., and Kendra, P. E. 2012. Susceptibility of Persea spp. and other Lauraceae to attack by redbay ambrosia beetle, Xyleborus glabratus (Coleoptera: Curculionidae: Scolytinae). Fla. Entomol. 95:783-787.

Ploetz, R. C., Konkol, J. L., Narvaez, T., Duncan, R. E., Saucedo, R. J., Campbell, A., Mantilla, J., Carrillo, D., and Kendra, P. E. 2017. Presence and prevalence of Raffaelea lauricola, cause of laurel wilt, in different species of ambrosia beetle in Florida, USA. J. Econ. Entomol. 110:347-354.

Rush, T. A., and Aime, M. C. 2013. The genus Meira-Phylogenetic placement and description of a new species. Antonie van Leeuwenhoek 103:1097-1106.

Smith, J. A., Dreaden, T. J., Hughes, M., Mayfield, A. E., III, Boone, A., Fraedrich, S. W., and Bates, C. 2009a. First report of laurel wilt disease caused by Raffaelea lauricola on sassafras in Florida and South Carolina. Plant Dis. 93:1079.

Smith, J. A., Mount, L. L., Mayfield, A. E., III, Bates, C. A., Lamborn, W. A., and Fraedrich, S. W. 2009b. First report of laurel wilt disease caused by Raffaelea lauricola on camphor in Florida and Georgia. Plant Dis. 93:198.

Sztejnberg, A., Paz, Z., Boekhout, T., Gafni, A., and Gerson, U. 2004. A new fungus with dual biocontrol capabilities: Reducing the numbers of phytophagous mites and powdery mildew disease damage. Crop Prot. 23: 1125-1129.

Tamura, K., and Nei, M. 1993. Estimation of the number of nucleotide substitutions in the control region of mitochondrial DNA in humans and chimpanzees. Mol. Biol. Evol. 10:512-526.

Travadon, R., Lecomte, P., Diarra, B., Lawrence, D. P., Renault, D., Oreda, H., Rey, P., and Baumgartner, K. 2016. Grapevine pruning systems and cultivars influence the diversity of wood-colonizing fungi. Fungal Ecol. 24:82-93.

White, T. J., Bruns, T., Lee, S., and Taylor, J. W. 1990. Amplification and direct sequencing of fungal ribosomal RNA genes for phylogenetics. Pages 315-322 in: PCR Protocols: A Guide to Methods and Applications. M. A. Innis, D. H. Gelfand, J. J. Sninsky, and T. J. White, eds. Academic Press, San Diego, CA.

Yasuda, F., Yamagishi, D., Akamatsu, H., Izawa, H., Kodama, M., and Otani, H. 2005. Fruit stain of Japanese pear caused by basidiomycetous, yeast-like fungi, Acaromyces ingoldii and Meira sp. Ann. Phytopathol. Soc. Jpn. 71: 156-165 (in Japanese). 